kê với độ tin cậy 99,99\%.

Sau 3 tuần điều trị, sự chênh lệch về mức độ tốt ở hai nhóm tiếp tục giảm khi tỷ lệ đạt kết quả tốt ở nhóm chứng tăng lên $78,1 \%$. Mắc dù vậy, tỷ lệ đạt kết quả tốt ở nhóm plasma vẫn cao hơn so với nhóm chứng, chiếm tỷ lệ là $93,8 \%$.

Qua những nhân xét trên ta có thể thấy, khi sử dunng plasma hổ trợ sau điều tri thì bênh nhân giảm rõ rệt các triệu chứng cơ năng, và đạt kết quả tốt sớm hơn so với nhóm chứng.

\section{KẾT LUÂN}

Sử dung tia plasma lanh trong hỗ trơ điều trị phẫu thuật nạo túi quanh răngở nhóm bệnh nhân có túi quanh răng từ 3 đến $5 \mathrm{~mm}$ có hiệu quả cao:

Giá trị trung bình chỉ số mảng bám răng (PI) sau 3 tuần giảm trong nhóm có can thiệp plasma chỉ số này giảm 1,8 cao hơn so với nhóm chứng, chỉ giảm 1,5 .

Trung bình chỉ số GI sau điều trị 3 tuần giảm 1,3 ở nhóm can thiệp plasma cao hơn so với 1,1 ở nhóm chứng.

Trung bình độ sâu túi quanh răng ở nhóm can thiệp có sử dụng plasma giảm xuống $1,8 \mathrm{~mm}$ (từ $3.1702 \pm 0.3732$ xuống $1.3827 \pm 0.3615$ ), trong khi nhóm chứng chỉ giảm $1,2 \mathrm{~mm}$ (từ $3.1821 \pm 0.3852$ xuống còn $1.9102 \pm 0.4055$ )

Tỷ lệ đạt kết quả tốt của nhóm can thiệp sau 3 ngày điêu trị là $96,9 \%$, ở nhóm chứng là $37,5 \%$. Tỷ lệ đạt kết quả tốt của nhóm can thiệp sau 3 tuần điêu trị chiếm 93,8\%, ở nhóm chứng là $78,1 \%$.

KIẾN NGHỊ. Qua nghiên cứu của chúng tôi có thể bước đầu nhận thấy rằng plasma rất hiệu quả và an toàn trong hỗ trợ sau điều trị nạo túi quanh răng; vì vậy nên đưa máy PlasmaMEDGAPDt phát tia plasma lạnh vào và xây dụng quy trình chuẩn trong thủ thuật nạo túi quanh răng.

\section{TÀI LIÊU THAM KHẢO}

1. Nguyễn Duy Thắng, Nguyễn Hồng Lới, và công sư (2020). Nghiên cứu kết quả điều trị viềm nướu có hố trợ Laser Diode trên bệnh nhân Hemophilia. Tạp chí y học lâm sàng, số 59/2020.

2. Vergani et al, 2004. Systemic use of metronidazole in the treatment of chronic periodontitis: a pilot study using clinical, microbiological, and enzymatic evaluation. Braz. oral res, $18(2), 121-127$.

3. Trân Thi Nga Liên (2012). Đánh giá hiêu quả điều trị bệnh viêm quanh răng mạn tính bằng phương pháp sử dụng laser diode. Luận văn thạc sỹ y học.

4. Kreisler M, Al Haj H, d'Hoedt B (2005). Clinical efficacy of semiconductor laser application as an adjunct to conventional scaling and root planing. Lasers Surg Med, 37(5):350-5.

5. Fridman $G$, Peddinghaus $M$, Balasubramanian $\mathbf{M}$, et al. Blood coagulation and living tissue sterilization by floating-electrode dielectric barrier discharge in air. Plasma Chem Plasma Process. 2006;26:425-42./

6. Kalghatgi SU, Fridman G, Cooper M, et al. Mechanism of blood coagulation by nonthermal atmospheric pressure dielectric barrier discharge plasma. IEEE Trans Plasma Sci.2007;35:1559-66.

\title{
KHẢO SÁT NỒNG ĐÔ̂ VITAMIN D Ở BÊNH NHÂN ĐÁI THÁO ĐƯờNG TYPE 2 CAO TUỔI Có LOÃNG XƯƠNG
}

\section{TÓM TẮT}

Muc tiêu: Khảo sát nồng độ vitamin $D$ và một số yếu tổ liên quan ở bệnh nhẩn đái tháo đường type 2 cao tuổi có loãng xương. Đối tượng và phương pháp: Nghiên cứu mô tả cắt ngang trên 70 bệnh nhân đái tháo đường type 2 cao tuổi có loãng xương đến khám và điều trị tại bệnh viện Lão khoa Trung ương từ tháng 10/2020 đến tháng 7/2021. Nồng độ vitamin $\mathrm{D}$ được đo bằng máy Cobas 6000 Modul e601 (Roche) tại khoa Xét nghiệm Bệnh viện Lão khoa Trung ương.

\footnotetext{
${ }^{1}$ Bệnh viện Lão khoa Trung ương

2 Trường Đại hoc Y Hà Nôi

Chịu trách nhiệm chính: Dương Thị Hồng Lý

Email: duonghongly1980@gmail.com

Ngày nhận bài: 2.8.2021

Ngày phản biên khoa hoc: 30.9.2021

Ngày duyệt bài: 7.10.2021
}

Kết quả: Nồng đô vitamin $D$ trung bình của bênh nhân nghiên cứu là 49,0 $\pm 17,3 \mathrm{nmol} / \mathrm{l}$, tỷ lệ thiếu vitamin $\mathrm{D}$ là $84,3 \%$. Nồng độ vitamin $\mathrm{D}$ ớ nhóm bệnh nhân tập thể dục thường xuyên, kiểm soát huyết áp và $\mathrm{HbA} 1 \mathrm{c}$ đat mục tiêu cao hơn có ý nghĩa thống kê so với nhóm không tập thể dục, kiểm soát huyết áp và HbA1c không đat mục tiêu $(p<0,05)$. Nồng độ vitamin D không có mối liền quan có ý nghĩa thống kê với nhóm tuổi, giới, BMI và kiểm soát lipid máu. Kết luận: Nồng độ vitamin $D$ trung bình của đối tượng nghiên cứu thẩp. Cần xét nghiệm tầm soát vitamin $\mathrm{D}$ và khuyến cáo tập thể dục, kiểm soát huyết áp và đường máu tốt ở bệnh nhân đái tháo đường type 2 cao tuổi có loãng xướng.

Tư khóa: Vitamin D, đái tháo đường type 2, loãng xương, người cao tuổi.

\section{SUMMARY}

INVESTIGATION OF VITAMIN D LEVELS IN 


\section{OLDER TYPE 2 DIABETICPATIENTS WITH OSTEOPOROSIS}

Objectives: To investigate vitamin D levels and some related factors in older type 2 diabetic patients with osteoporosis. Subjects and methods: a crosssectional descriptive study on 70 older type 2 diabetic patients with osteoporosis examined and treated at the National Geriatric Hospital from October 2020 to July 2021. Vitamin D levels were measured using a Cobas 6000 Module e601 (Roche) instrument at the Laboratory department of the National Geriatric Hospital. Results: The average vitamin D concentration of the participants was $49.0 \pm 17.3$ $\mathrm{nmol} / \mathrm{l}$. The rate of vitamin D deficiency was $84.3 \%$. Vitamin $D$ levels in the group of patients who exercised regularly, controlled blood pressure and $\mathrm{HbA1c}$ were statistically significantly higher than those who did not exercise, uncontrolled blood pressure and HbA1c ( $p<0.05)$. Vitamin D levels had no statistically significant relationship with age group, gender, body mass index and blood lipid control. Conclusion: The average vitamin D concentration of the study subjects was low. Vitamin D screening tests, exercise regularly, good control of blood pressure and blood glucoseare recommended in older type 2 diabetic patients with osteoporosis.

Keywords: Vitamin D, type 2 diabetes, osteoporosis, older.

\section{I. ĐẶT VẤN ĐỀ}

Hiện nay, với tốc độ già hóa dân số nhanh và những thay đổi trong lối sống hiện đại, đái tháo đường (ĐTĐ) type 2 và loãng xương đã trở thành những bệnh lý mạn tính thường gặp và có tỷ lệ đồng mắc cao ở người cao tuổi. Trên thế giới cũng như ở Việt Nam đã nghi nhận, tỷ lệ loãng xương ở bệnh nhân ĐTĐ type 2 cao tuổi khá cao, chiếm tới43,0\% - 53,7\% [1],[5].

Vitamin D là nhóm vitamin tan trong dâu, có vai trò quan trọng trong nhiêuu chức năng sinh lý, bao gồm cân bằng nội môi calci - phốt pho, chuyển hóa xương, kích thích bài tiết insulinvà giảm đề kháng insulin. Thiếu vitamin D làm tăng nguy cơcủa hội chứng chuyển hóa cũng như ĐTÐ type 2. Bên cạnh đó, thiếu vitamin $D$ còn làm tăng nguy cơ loãng xương, tăng nguy cơ té ngã và gãy xương ở người cao tuổi [4]. Vấn đề này càng trâm trọng hơn khi tình trạng thiếu vitamin $D$ xảy ra ở bệnh nhân ĐTĐ type 2 có loãng xương. Chính vì vậy, việc xác định nông độ vitamin $D$ huyết tương ở bệnh nhân ĐTĐ type2 cao tuổi có loãng xương rất quan trọng, giúp cho việc phòng ngửa tình trạng thiếu vitamin $D$, giúp giảm nguy cơ gãy xương do loãng xương ở người cao tuổi mắc ĐTĐ type 2 .

Trên thế giới đã có những nghiên cứu cho thây nồng độ vitamin $D$ ở bệnh nhân ĐTĐ type 2 có loãng xương đều thấp. Nghiên cứu của
WangZhe cho thấy, nồng độ vitamin $D$ huyết tương ở người cao tuổi mắc ĐTĐ type 2 và loãng xương là 26,35 \pm 6,92 nmol/l $(10,54 \pm 2,77$ $\mathrm{ng} / \mathrm{ml}$ ) [8]. Theo MathenPratheesh George và cộng sự, nồng độ viamin D ở bệnh nhân ĐTĐ type 2 có loãng xương cột sống thắt lưng là $50,37 \pm 30 \mathrm{nmol} / \mathrm{l}(20,19 \pm 12 \mathrm{ng} / \mathrm{ml})$ và loãng xương cổ xương đùi là $56,32 \pm 28,50 \mathrm{nmol} / \mathrm{l}$ $(22,53 \pm 11,4 \mathrm{ng} / \mathrm{ml})[6]$

Tại Việt Nam, nồng độ vitamin $D$ ở bệnh nhân ĐTĐ type 2 còn chưa được quan tâm và có rất ít nghiên cứu về vấn đề này, đặc biệt trên đối tượng người cao tuổi có mắc kèm bệnh lý loãng xương. Chính vì vậy, chúng tôi tiến hành nghiên cứu đề tài này với mục tiêu khảo sát nông độ vitamin $D$ ở bệnh nhân ĐTĐ type 2 cao tuổi có loãng xương và nhận xét một số yếu tố liên quan đến nồng độ vitamin $D$ ở nhóm đối tượng trên.

II. ĐỐI TƯỢNG VÀ PHƯƠNG PHÁP NGHIÊN CỨU

2.1. Đối tượng nghiên cứu: gồm 70 bệnh nhân được chẩn đoán ĐTĐ type2 có loãng xương khám và điều trị tại bệnh viện Lão khoa Trung ương từ tháng 10/2020 đến tháng 7/2021.

Tiêu chuẩn chọn bệnh nhân:

- Tuổi: $\geq 60$ tuổi.

- Bệnh nhân được chẩn đoán bệnh ĐTĐ type 2 theo tiêu chuẩn của Hiệp hội đái tháo đường Hoa Kỳ 2019 [2].

- Bệnh nhân được chẩn đoán loãng xương theo tiểu chuẩn của Tổ chức $Y$ tế Thế giới năm 2002[3]: Đo mật độ xương bằng phương pháp DEXA, với T-score <-2,5 SD.

- Bệnh nhân và người nhà bệnh nhân đồng ý tham gia nghiên cứu.

Tiêu chuẩn loại trừ:

- Bệnh nhân có các biến chứng cấp tính của bệnh ĐTĐ hoặc các bệnh lý cấp tính nặng.

- Bệnh nhân đã được điêuu trị thuốc chống động kinh, thuốc gây độc tế bào, vitamin $D$ và các chế phẩm có chứa vitamin $\mathrm{D}$.

- Mắc các bệnh lý nội tiết: Suy giáp, cường giáp, hội chứng Cushing.

- Bệnh nhân bị cắt dạ dày, viêm đường tiêu hóa man tính.

- Bệnh thận mạn giai đoạn 4, 5.

- Suy gan.

- Bệnh nhân quá già yếu, những bệnh nhân giai đoạn cuối.

- Bệnh nhân suy dinh dưỡng với BMI < 18.5 kg/m2

- Không thu thập đủ các dữ liệu nghiên cứu.

2.2. Phương pháp nghiên cứu: Mô tả cắt ngang, phương pháp chọn mẫu thuận tiện. Các biến số nghiên cứu bao gồm: tuổi, giới, huyết 
áp, chiều cao, cân nặng, chỉ số khối cơ thể (Body mass index - BMI), khu vực sống, tập thể dục, $\mathrm{HbA1c}$, lipid máu 4 thành phần. Nồng độ vitamin D được đo bằng máy Cobas 6000 Modul e601 của hãng Roche theo nguyên lý cạnh tranh, sử dụng công nghệ điện hóa phát quang (electrochemiluminescence immunoassay) tại khoa Xét nghiệm Bệnh viện Lão khoa Trung ương. Chẩn đoán thiếu vitamin $D$ khi nồng độ vitamin $D$ huyết tương nhỏ hơn 75 nmol/l (30 $\mathrm{ng} / \mathrm{ml})[4]$.

Xử lý số liệu: Số liệu được xử lý và phân tích bằng phần mềm thống kê y học SPSS 25.0. Sử dụng các thuật toán: tính tỷ lệ phần trăm, tính giá trị trung bình. Sử dụng t-test để so sánh hai trung bình, sự khác biệt có ý nghĩa thống kê khi $p<0,05$.

\section{KẾT QUẢ NGHIÊN CỨU}

Qua nghiên cứu 70 bệnh nhân cao tuổi được chẩn đoán ĐTĐ type 2 có loãng xương đến khám và điều trị tại Bệnh viện Lão khoa Trung ương từ tháng 10/2020 đến tháng 7/2021, chúng tôi thu được kết quả như sau:

3.1. Đặc điểm chung của đối tượng nghiên cứu

Bảng 3.1. Đặc điểm chung của đôi tượng nghiên cứu.

\begin{tabular}{|c|c|c|}
\hline \multicolumn{2}{|c|}{ Đặc điếm } & Giá trị \\
\hline \multicolumn{2}{|c|}{ Tuối trung bình (năm) } & $75,81 \pm 6,86$ \\
\hline \multirow{2}{*}{ Giới } & Nam $(n=6)$ & $8,6 \%$ \\
\cline { 2 - 3 } & Nữ $(n=64)$ & $91,4 \%$ \\
\hline
\end{tabular}

\begin{tabular}{|c|c|}
\hline BMI $(\mathrm{kg} / \mathrm{m} 2)$ & $22,63 \pm 2,10$ \\
\hline HATT $(\mathrm{mmHg})$ & $133,71 \pm 10,92$ \\
\hline HATTr mmHg) & $79,97 \pm 10,84$ \\
\hline Thời gian mắc $Đ T Ð$ (năm) & $8,93 \pm 4,18$ \\
\hline Đường máu lúc đói $(\mathrm{mmol} / \mathrm{l})$ & $8,64 \pm 2,15$ \\
\hline HbA1c $(\%)$ & $7,94 \pm 1,49$ \\
\hline Cholesterol $(\mathrm{mmol} / \mathrm{l})$ & $4,61 \pm 1,15$ \\
\hline Triglycerid $(\mathrm{mmol} / \mathrm{l})$ & $2,16 \pm 0,91$ \\
\hline HDL-C $(\mathrm{mmol} / \mathrm{l})$ & $1,14 \pm 0,32$ \\
\hline LDL-C (mmol/l) & $2,47 \pm 1,06$ \\
\hline BMD CXĐ & $0,710 \pm 0,211$ \\
\hline BMD CSTL & $0,635 \pm 0,061$ \\
\hline T -score CXĐ & $-0,847 \pm 1,104$ \\
\hline T -score CSTL & $-3,183 \pm 0,486$ \\
\hline
\end{tabular}

BMI: chỉ số khối cơ thể, HATT: huyết áp tâm thu, HATTr: huyết áp tâm trương, BMD: mật độ xương, CXĐ: cổ xương đùi, CSTL: cột sống thắt lưng.

Tuổi trung bình bệnh nhân trong nghiên cứu của chúng tôi là $75,81 \pm 6,86$ tuổi. Đa số bệnh nhân là nữ giới, chiếm 91,4\%.

3.2. Nồng độ vitamin $D$ và tỷ lệ thiếu vitatmin $\mathrm{D}$ của đối tượng nghiên cứu

Bảng 3.2. Nồng độ Vitamin D huyêt tương và tỷ lệ thiếu vitamin $D$ của đôi tượng nghiên cứu.

\begin{tabular}{|c|c|}
\hline Chỉ số & Giá trị \\
\hline Nồng độ vitamin $D(T B \pm S D)$ & $49,0 \pm$ \\
$17,3 n m o l / l$ \\
\hline Thiếu vitamin D $(n=59)$ & $84,3 \%$ \\
\hline
\end{tabular}

Nồng độ vitamin $\mathrm{D}$ trung bình của bệnh nhân nghiên cứu là $49,0 \pm 17,3 \mathrm{nmol} / \mathrm{l}$, tỳ lệ thiếu vitamin D là $84,3 \%$.

\subsection{Một số yếu tố liên quan với nồng độ vitamin $D$}

\section{Bảng 3.3. Nồng độ vitamin D huyêt tương và một số yêu tố liên quan}

\begin{tabular}{|c|c|c|c|c|}
\hline \multicolumn{2}{|c|}{ Yếu tố } & \multirow{2}{*}{$\begin{array}{c}\text { Số bệnh nhân } \\
10\end{array}$} & \multirow{2}{*}{$\begin{array}{c}\text { Vitamin D (nmol/l) } \\
44,21 \pm 13,88\end{array}$} & \multirow{4}{*}{$\begin{array}{c}\mathbf{p} \\
>0,05\end{array}$} \\
\hline \multirow{3}{*}{ Nhóm tuổi } & $60-69$ & & & \\
\hline & $70-79$ & 34 & $48,79 \pm 16,88$ & \\
\hline & $\geq 80$ & 26 & $51,14 \pm 19,14$ & \\
\hline \multirow{2}{*}{ Giới } & Nam & 6 & $49,93 \pm 18,91$ & \multirow{2}{*}{$>0,05$} \\
\hline & Nư & 64 & $48,92 \pm 17,30$ & \\
\hline \multirow{2}{*}{$\begin{array}{l}\text { Khu vực } \\
\text { sống }\end{array}$} & Thành Thị & 51 & $48,70 \pm 16,88$ & \multirow{2}{*}{$>0,05$} \\
\hline & Nông thôn & 19 & $49,84 \pm 18,81$ & \\
\hline \multirow{2}{*}{ Tập thể dục } & Có & 8 & $78,20 \pm 3,61$ & \multirow{2}{*}{$<0,05$} \\
\hline & Không & 62 & $45,24 \pm 14,52$ & \\
\hline \multirow{2}{*}{$\mathrm{HbA1c}$} & $<7,5 \%$ & 31 & $59,94 \pm 15,00$ & \multirow{2}{*}{$<0,001$} \\
\hline & $\geq 7,5 \%$ & 39 & $40,32 \pm 13,82$ & \\
\hline \multirow{2}{*}{ BMI } & $<23$ & 44 & $47,64 \pm 17,04$ & \multirow{2}{*}{$>0,05$} \\
\hline & $\geq 23$ & 26 & $51,33 \pm 17,83$ & \\
\hline \multirow{2}{*}{ Huyết áp } & $<140 / 90 \mathrm{mmHg}$ & 50 & $52,33 \pm 17,00$ & \multirow{2}{*}{$<0,05$} \\
\hline & $\geq 140 / 90 \mathrm{mmHg}$ & 20 & $40,70 \pm 15,46$ & \\
\hline \multirow{2}{*}{$\begin{array}{l}\text { Kiếm soát } \\
\text { lipid máu }\end{array}$} & Không đạt & 57 & $48,36 \pm 16,43$ & \multirow{2}{*}{$>0,05$} \\
\hline & Đat muc tiêu & 13 & $51,85 \pm 21,21$ & \\
\hline
\end{tabular}

Nồng độ vitamin $D$ ở nhóm bênh nhân tâp thể dục thường xuyên, kiểm soát huyết áp và HbA1c đat mục tiêu cao hơn có ý nghĩa thống kê so với nhóm không tập thể dục, kiểm soát huyết áp và 
HbA1c không đạt mục tiêu $(p<0,05)$. Nồng độ vitamin $D$ không có mối liên quan có ý nghĩa thống kê với nhóm tuổi, giới, BMI và kiểm soát lipid máu.

\section{BÀN LUẬN}

Người cao tuổi có nhiều nguyên dẫn đến thiếu vitamin D như: giảm tổng hợp vitamin $\mathrm{D}$ ở da, giảm các hoạt động ngoài trời, giảm tiêu thụ và hấp thu vitamin $D$, tác dụng không mong muốn của một số thuốc. Chính vì vậy, người cao tuổi có nguy cơ cao thiếu vitamin $D$, đắc biệt là đối tượng người cao tuổi có bệnh lý kèm theo nhưĐị̄, loãng xương. Nghiên cứu của chúng tôi cho thây nồng độ vitamin $D$ ở bệnh nhân ĐTĐ type 2 cao

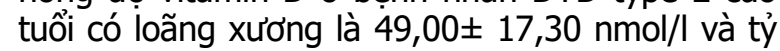
lệ thiếu vitamin $D$ chiếm đến $84,3 \%$. Như vậy, phần lớn bệnh nhân cao tuổi mắc bệnh ĐTĐ type 2 kết hợp loãng xương có thiếu vitamin $D$ và nồng độ vitamin $D$ ở nhóm đối tượng này khá thấp. Kết quả của chúng tôi cũng phù hợp với kết quả của một số nghiên cứu khác. Nghiên cứu của Wang Zhe tại Trung Quốc cho thấy, nồng độ vitamin D huyết tương ở người cao tuổi mắc ĐTĐ่ type 2 và loãng xương là $26,35 \pm 6,92 \mathrm{nmol} / \mathrm{l}(10,54 \pm$ $2,77 \mathrm{ng} / \mathrm{ml}$ ) [8]. Tác giả Mathen Pratheesh George và cộng sư nghiên cứu trên 150 bệnh nhân ĐTĐ type2 tại Ẩn Độ có độ tuổi trung bình là 51,29 tuổi cho thẩy, nồng độ vitamin D ở bệnh nhân ĐTĐ type 2 có loãng xương cột sống thắt lưng là 50,37 $\pm 30 \mathrm{nmol} / \mathrm{l}(20,19 \pm 12 \mathrm{ng} / \mathrm{ml})$ và loãng xương cổ xương đùi là $56,32 \pm 28,50 \mathrm{nmol} / \mathrm{l}(22,53 \pm$ $11,4 \mathrm{ng} / \mathrm{ml}$ ) [6].

Với vai trò sinh lý của vitamin $D$, thông qua việc liên kêt dạng hoạt động của vitamin $D$ $1,25(\mathrm{OH}) 2 \mathrm{D}$ với các thụ thể vitamin $\mathrm{D}$ có ở hầu hết mô trong cơ thể, vitamin $D$ được cho là có ảnh hưởng đến đường máu thông qua các cơ chế tăng tổng hợp và bài tiết insulin; giảm sự đề kháng insulin cũ̃ng như giảm đáp ứng viêm hệ thống. Chính vì vậy, thiếu vitamin $D$ có ảnh hưởng tiêu cực đến việc kiểm soát đường máu ở bệnh nhân ĐTÐ type 2 . Trong nghiên cứu của chúng tôi, những bệnh nhân kiểm soát đường máu kém (HbA1c $\geq 7,5 \%$ ) có nồng độ vitamin $D$ thấp hơn ở nhóm kiểm soát đường máu tốt (HbA1c $<7,5 \%)$. Kết quả nghiên cứu của Zhao Hang và cộng sự cũng cho thây giá trị HbA1c cao hơn ở nhóm ĐTÐ type 2 có thiếu vitamin $D$ so với nhóm không thiếu vitamin $D$ và nồng độ vitamin $D$ có mối tương quan nghịch với giá trị $\operatorname{HbA} 1 \mathrm{c}(r=-0,254$ và $p<0,001)[9]$.

Nghiên cứu của chúng tôi cũng nghi nhận, ở nhóm bệnh nhân đạt huyết áp mục tiêu (huyết áp <140/90 mmHg) có nồng độ vitamin $D$ cao hơn nhóm không đạt huyết áp mục tiêu (huyết áp $\geq 140 / 90 \mathrm{mmHg}$ ). Tác giả Sivritepe Ridvan khi nghiên cứu trên 208 bệnh nhân ĐTĐ type 2 có thiếu vitamin $D$ cho thấy huyết áp tâm thu và huyết áp tâm trương đều cao hơn ở nhóm có nồng độ vitamin $D<25 \mathrm{nmol} / \mathrm{l}(10 \mathrm{ng} / \mathrm{ml})[8]$. Cơ chế gây tăng huyết áp có thể dothiếu vitamin $D$ gây kích hoat hệ thống renin-angiotensinaldosterone làm tăng sản xuất renin và angiotensin II, thiếu vitamin $D$ gây kích thích tuyến cận giáp tăng tiết PTH, đônng thời thiếu vitamin $\mathrm{D}$ cũng gây rối loạn chức năng nội mô, giảm tổng hợp nitric oxide làm giảm sự giãn mạch dẫn đến tăng huyết áp[4].

Luyện tập thể dục thường xuyên đóng một vai trò quan trọng giúp kiểm soát đường máu, huyết áp cũng như phòng tránh một số bệnh lý ớ người cao tuổi. Trong nghiên cứu của chúng tôi cho thấy ở nhóm tập thể dụcthường xuyên có nồng độ vitamin $D$ cao hơn nhóm không tập thể dục với sự khác biệt có ý nghĩa thống kê $(78,20$ $\pm 3,61 \mathrm{nmol} / \mathrm{l}$ so với $45,24 \pm 14,52, \mathrm{p}<0,05)$. Một trong những tác dụng tích cực của tập thể dục với vitamin $D$ đó là khi tập luyện ngoài trời làm tăng cường khả năng tổng hợp vitamin $D$ ở da do có tiếp xúc với ánh nắng mặt trời. Tuy nhiên, vì cỡ mẫu nghiên cứu nhỏ, và do ảnh hưởng của dịch Covid-19 nên số bệnh nhân tham gia tập thể dục trong nghiên cứu của chúng tôi ít (8/70 bệnh nhân); các bệnh nhân thường tập thể dục vào khoảng thời gian sáng sớm và chiều tối, không tiếp xúc với ánh nắng mặt trời nên vấn đề này cần đánh giá thêm trong những nghiên cứu lớn hơn.

Tình trạng vitamin $D$ được cho là có liên quan đến tuổi, giới, khu vực sinh sống, BMI và lipid máu đã được ghi nhận trong các nghiên cứu trước đây. Tuy nhiên, trong nghiên cứu của chúng tôi không tìm thây mối liên quan giữa nồng độ vitamin $D$ với các yếu tố trên. Có thể có sự khác biệt này là do mẫu nghiên cứu nhỏ, nên những vấn đề này cần được làm sáng tỏ trong những nghiên cứu với cỡ mẫu lớn hơn.

\section{KẾT LUẬN}

Nồng độ vitamin $D$ trung bình của đối tượng nghiên cứu thấp, tỉ lệ thiếu vitamin $D$ khá cao $(84,3 \%)$. Cần xét nghiệm tầm soát vitamin $D$ và khuyến cáo tập thể dục thường xuyên, kiểm soát huyết áp và đường máu đạt mục tiêu ở bệnh nhân đái tháo đường type 2 cao tuổi có loãng xương.

TÀI LIẸU THAM KHẢO

1. Nguyễn Thị Phương Thùy (2013). "Nghiên cứu 
tình trạng loãng xương ở bệnh nhân đái tháo đường týp 2 cao tuô̂i". Luận văn Thạc sỹ y học,Trường Đại học Y Hà Nội

2.American Diabetes Association(2019). "Classification and diagnosis of diabetes: standards of medical care in diabetes -2019".Diabetes Care. 2019; 42(Supplement 1): S13-S28.

3. Cosman Felicia, et al (2014). "Clinician's guide to prevention and treatment of osteoporosis". Osteoporosis International.2014; 25(10): 2359-2381.

4. Garg Mk, et al (2012). "Vitamin D Deficiency in Elderly: Implications, Prevention and Treatment".Journal of The Indian Academy of Geriatrics. 2012; 8(2): 77-82.

5. Kanazawa Ippei, et al (2019). "Osteoporosis and vertebral fracture are associated with deterioration of activities of daily living and quality of life in patients with type 2 diabetes mellitus". Journal of Bone and Mineral Metabolism. 2019; 37(3): 503-511.
6. Mathen Pratheesh George, et al (2015). "Decreased bone mineral density at the femoral neck and lumbar spine in South Indian patients with type 2 diabetes".Journal of Clinical and Diagnostic Research.2015; 9(9): OC08 - OC12

7. Sivritepe Rıdvan, Basat Sema, and Ortaboz Damla (2019). "Association of vitamin D status and the risk of cardiovascular disease as assessed by various cardiovascular risk scoring systems in patients with type 2 diabetes mellitus". The Aging Male.2019; 22(2): 156-162.

8. Wang Zhe, et al (2019). "Correlation of serum 25-hydroxy vitamin D with Leptin and visceral fat area in T2DM patients combined with osteoporosis". Biomedical Research. 2019; 30(4)

9. Zhao Hang, et al (2020). "The relationship between vitamin $D$ deficiency and glycated hemoglobin levels in patients with type 2 diabetes mellitus". Diabetes Metab Syndr Obes.2020; 13: 3899.

\section{NHÂN XÉT ĐĂC ĐIỂM LÂM SÀNG, CÂN LÂM SÀNG VÀ KẾT QUẢ ĐIỀU TRI XẠ PHẪU U MÀNG NÃO Độ CAO ĐÃ PHẪU THUẤT}

\section{TÓM TẮT}

Nghiên cứu nhằm nhận xét đặc điểm lâm sàng, cận lâm sàng và kết quả điều trị xạ phẫu u màng não đồ cao đã phẫu thuật. Đối tượng và phương pháp nghiên cứu: Nghiên cứu mô tả trên 24 bệnh nhân u màng não độ cao đã được phẫu thuât từ tháng 7/2019 đến 7/2021. Bệnh nhẩn được xạ phẫu bằng máy Gamma Knife thế hệ Icon. Chúng tổi phân tích các đăc điểm lâm sàng, cận lâm sàng và sự kiểm soát u. Kết quả: Trong nghiên cứu của chúng tôi, tuổi trung bình là $57,46 \pm 14,49$, tỷ lệ nam/nữ là $1 / 2 ; 87,5 \%$ có triệu chứng thần kinh; 87,5\% u màng não độ II, 12,5\% u màng não độ III; $58,3 \%$ u ở vòm sọ. Với thời gian theo dõi trung bình 13 tháng ( 7 - 21tháng), có 2 bệnh nhân u màng não độ II và 1 bệnh nhân u màng não đô III tái phát. Tỷ lệ kiểm soát tại thời điểm 1 năm là 94,1\%. Kết luân: Xạ phẫu Gamma Knife là phương pháp hiệu quả giúp kiểm soát tại chỗ u màng não độ cao. Knife.

Tư khóa: xạ phẫu, u màng não độ cao, Gamma

\section{SUMMARY \\ CLINICAL CHARACTERISTICS AND RESULTS OF RADIOSURGERY FOR POST- OPERATIVE HIGH GRADE MENINGIOMAS}

\author{
*Bênh viện $K$ \\ Chiu trách nhiệm chính: Phan Thanh Dương \\ Email: phanthanhduong0705@gmail.com \\ Ngày nhận bài: 4.8.2021 \\ Ngày phản biện khoa học: 1.10 .2021 \\ Ngày duyệt bài: 8.10.2021
}

Phan Thanh Dương1, Nguyễn Đức Liên ${ }^{1}$, Phạm Hồng Phúc ${ }^{1}$, Nguyễn Minh Thuận ${ }^{1}$

Our study aimed to evaluate the clinical characteristic and outcome of radiosurgery for postoperative high grade meningiomas. Methods: The authors reviewed records from 24 patients with histologically proven high-grade meningioma from July 2019 to July 2021. Patients were treated by stereotactic radiosurgery using Leksell Gamma Knife ICON unit (Elekta AB). We analyzed clinical, preclinical characteristics and local tumor control. Results: In our study, the mean age was $57,46 \pm$ 14,49 , male/female ratio was $1 / 2 ; 87,5 \%$ had neurological symptoms; $87,5 \%$ had atypical meningioma, $12,5 \%$ had anaplastic meningioma; $58,3 \%$ occur at the cerebral convexities. With an average follow-up time of 13 months (7-21 months), 2 grade II meningioma cases and 1 grade III meningioma case developed recurrence. The tumor control rate at 1 year was $94,1 \%$. Conclusion: Gamma Knife radiosurgery is an effective method for local control of high-grade meningiomas.

Key words: radiosurgery, high grade meningioma, Gamma Knife.

\section{I. Đă̆T VẤN ĐỀ}

U màng não là khối u nguyên phát của thần kinh trung ương hay găp thứ hai, chiếm tỷ lê 13 - 16\% khối u nội sọi. Theo phân loại của tổ chức $Y$ tế thế giới, u màng não được chia là 3 độ, trong đó khoảng $90 \%$ là u màng não độ I, 5$15 \%$ u màng não độ II, 1-3\% u màng não độ III². Phẫu thuâat là phương pháp điều trị cơ bản nhất của $u$ màng não với mục tiêu cắt bỏ hoàn toàn khối u. Sau phẫu thuật, u màng não lành 